\title{
Furosemide stimulation of parathormone in humans: role of the calcium-sensing receptor and the renin-angiotensin system
}

\author{
Marie-Eve Muller $^{1}$ • Valentina Forni Ogna ${ }^{1} \cdot$ Marc Maillard $^{1}$ - Candice Stoudmann ${ }^{2}$. \\ Carole Zweiacker $^{1}$ • Christiane Anex ${ }^{1} \cdot$ Grégoire Wuerzner $^{1}$ • Michel Burnier ${ }^{1}$. \\ Olivier Bonny ${ }^{1,2}$
}

Received: 29 October 2014 / Revised: 1 June 2015 / Accepted: 7 June 2015 /Published online: 20 June 2015

(C) Springer-Verlag Berlin Heidelberg 2015

\begin{abstract}
Interactions between sodium and calcium regulating systems are poorly characterized but clinically important. Parathyroid hormone (PTH) levels are increased shortly after furosemide treatment by an unknown mechanism, and this effect is blunted by the previous administration of a calcimimetic in animal studies. Here, we explored further the possible underlying mechanisms of this observation in a randomized crossover placebo-controlled study performed in 18 human males. Volunteers took either cinacalcet $(60 \mathrm{mg})$ or placebo and received a $20 \mathrm{mg}$ furosemide injection $3 \mathrm{~h}$ later. Plasma samples were collected at 15-min intervals and analyzed for intact PTH, calcium, sodium, potassium, magnesium, phosphate, plasma renin activity (PRA), and aldosterone up to $6 \mathrm{~h}$ after furosemide injection. Urinary electrolyte excretion was also monitored. Subjects under placebo presented a sharp increase in PTH levels after furosemide injection. In the presence of cinacalcet, PTH levels were suppressed and marginal increase of PTH was observed. No significant changes in electrolytes and urinary excretion were identified that could
\end{abstract}

Marie-Eve Muller, Valentina Forni Ogna, Michel Burnier and Olivier Bonny contributed equally to this work.

Electronic supplementary material The online version of this article (doi:10.1007/s00424-015-1714-4) contains supplementary material, which is available to authorized users.

Olivier Bonny

Olivier.Bonny@unil.ch

1 Service of Nephrology and Hypertension, Department of Medicine, Lausanne University Hospital, Lausanne, Switzerland

2 Department of Pharmacology and Toxicology, University of Lausanne, Lausanne, Switzerland explain the furosemide-induced increase in PTH levels. PRA and aldosterone were stimulated by furosemide injection but were not affected by previous cinacalcet ingestion. Expression of $\mathrm{NKCC1}$, but not $\mathrm{NKCC} 2$, was found in parathyroid tissue. In conclusion, our results indicate that furosemide acutely stimulates PTH secretion in the absence of any detectable electrolyte changes in healthy adults. A possible direct effect of furosemide on parathyroid gland needs further studies.

Keywords Mineral metabolism - Calcium-sensing receptor . Renin-angiotensin-aldosterone system $\cdot$ Cinacalcet .

Furosemide

\section{Introduction}

Several experimental and clinical studies have reported that furosemide increases plasma parathyroid hormone (PTH) after acute or chronic furosemide treatment $[6,10$, 18]. As of today, the precise mechanism whereby furosemide stimulates PTH remains largely unknown. Increased calciuria induced by furosemide has been proposed as a possible explanation for this phenomenon, but how calciuria can actually stimulate PTH secretion is obscure, as no significant change in serum calcium has been reported so far $[6,27]$. Thus, alternative mechanisms should be considered in order to explain the effect of furosemide on PTH secretion.

If the mechanism remains unknown, furosemide-induced PTH secretion has well-recognized consequences which have been observed in animals and humans $[13,24,30]$. Indeed, rats develop nephrocalcinosis only a few days after the beginning of a furosemide treatment [24], and chronic administration of furosemide has been associated with the development 
of nephrocalcinosis in neonates and infants $[13,30]$. Moreover, increasing evidence, in human adults, show that furosemide may also cause medullary nephrocalcinosis in a dosedependent manner [17]. Interestingly, nephrocalcinosis did not occur in parathyroidectomized rats treated by furosemide in a preliminary study by Alon et al. [25]. An indirect argument in favor of PTH implication in the nephrocalcinosis observed in furosemide-treated rats is the recent observation that simultaneous administration of furosemide and a calcimimetic blunts this effect [18]. Indeed, NPS R-467, a calcimimetic, is preventing nephrocalcinosis in young rats [25], further emphasizing the contribution of PTH rather than calciuria in inducing nephrocalcinosis after furosemide treatment. These recent findings also point to a possible role of the calciumsensing receptor as a potential mediator of the effect of furosemide on PTH. Accordingly, we and others have reported that the administration of a calcimimetic to mice and rats decreases the activity of the renin-angiotensin system (RAS) and blunts the furosemide-induced increase of PTH and renin [18], suggesting that the renin-angiotensin-aldosterone might also be involved. As of today, most of the observations made with calcimimetics have been done in animals, and whether they occur similarly in humans has not been investigated.

This randomized placebo-controlled crossover study was designed to investigate the mechanisms mediating the acute effect of a single dose of furosemide on PTH in healthy adult males. In addition, we have assessed a possible interaction between cinacalcet, renin, aldosterone, and PTH in response to furosemide.

\section{Subjects and methods}

The study was conducted on healthy volunteers, recruited through advertisements in the Lausanne University Hospital and at the Lausanne University and Federal Polytechnical School sites. Informed consent was obtained from all individual participants included in the study.

Eighteen Caucasian males aged 18 to 45 years, nonsmokers, and with no concomitant treatment were enrolled in the study. To be included, they should have had, at the screening visit, a BMI $>18$ and $<25 \mathrm{~kg} / \mathrm{m}^{2}$, normal clinical examination, normal 12-lead ECG, normal blood pressure $(<140 / 90 \mathrm{mmHg}$ ), and heart rate (HR) $\geq 45$ and $\leq 90$ beats/ min after $5 \mathrm{~min}$ in supine position measured three times at 2min intervals on the left arm. Finally, the subjects had to be able to understand the written information and the written consent form and must have given written, dated, and signed consent before starting any trial procedure.

We excluded subjects with electrolyte disturbances, positive serology for HIV, HBV, or HCV, positive detection of drugs in urine, any history of diseases or clinically significant conditions, and drug therapy.
All procedures performed were in accordance with the ethical standards of the institutional and/or national research committee and with the 1964 Helsinki declaration and its later amendments. The protocol was submitted and approved by the ethical committee of the Canton de Vaud, Switzerland, and the Swiss drug authority "Swissmedic." The study was registered at ClinicalTrial.gov (ID NCT01519037).

\section{Study protocol}

The protocol included two similar 4-day periods with 3 days (D-3 to D-1) of run-in and 1 day of investigation (D0). According to the crossover design, subjects were randomly assigned to receive, in a blinded manner, either a single dose of $60 \mathrm{mg}$ cinacalcet or placebo, orally, in the first and second period respectively. From D-3 to D-1, the volunteers were asked to ingest a low-salt diet in order to achieve a salt intake of $<3 \mathrm{~g} / 24 \mathrm{~h}$ ( $50 \mathrm{mmol}$ of $\mathrm{Na}^{+}$per day). This was done to standardize salt intake and to stimulate the renin-angiotensin system. Compliance to the diet was verified using repeated 24-h urine collections.

The investigation day (D0) started at 07:45 with a brief clinical health check. Subjects were asked to empty their bladder, and then, a venous catheter was inserted in a forearm vein for repeated blood samplings. Participants remained in supine position for the whole day, except for voiding. Blood draw was always performed before voiding. Heart rate (HR) and blood pressure (BP) were measured every 30 min (every 15 min during the first hour after furosemide administration). A standardized hydration protocol $(2 \mathrm{ml} / \mathrm{kg}$ of water every hour) was used all along the day.

At 08:00 (H-3), participants received either placebo or $60 \mathrm{mg}$ cinacalcet with a light breakfast. The medication was prepared by the hospital pharmacy and was blinded to both, investigators and subjects. Twenty milligrams of furosemide was injected intravenously immediately after the 11:00 urine collection. BP and HR were measured every 15 min during $1 \mathrm{~h}$ after iv furosemide injection. The following parameters were monitored in blood (every $15 \mathrm{~min}$ ): sodium, potassium, total calcium, ionized calcium, albumin, magnesium, and phosphate, and in urine (every 15-30 min): sodium, potassium, total calcium, creatinine, uric acid, and urea. The samples were immediately processed, aliquoted, and frozen.

Thirteen subjects completed the protocol as indicated above (and are called furosemide positive $(\mathrm{F}+)$ ). A second cluster of five participants following the same design was added afterwards without administration of furosemide in order to assess the spontaneous variations in PTH levels and are described as "furosemide negative ( $\mathrm{F}-)$ ". According to the crossover design of the study, four subgroups were analyzed, i.e., the cinacalcet/furosemide positive $(\mathrm{C} / \mathrm{F}+)$ and placebo/ furosemide positive $(\mathrm{P} / \mathrm{F}+)(n=13)$ and cinacalcet/ furosemide negative $(\mathrm{C} / \mathrm{F}-)$ and placebo/furosemide negative 
$(\mathrm{P} / \mathrm{F}-)(n=5)$. In the $\mathrm{F}+$ group, six volunteers were assigned first to cinacalcet then to placebo. In the $\mathrm{F}-$ group, three participants received cinacalcet first.

Laboratory analysis Urine and blood samples were measured at the Central Chemical Laboratory of the Lausanne University Hospital (CHUV, Lausanne, Vaud, Switzerland) using standard methods.

Serum sodium (intra- and inter-batch CV: 0.20 and $0.90 \%$, respectively), urine sodium ( 0.30 and $0.60 \%$ ), serum potassium $(0.20$ and $0.90 \%)$, and urine potassium $(0.40$ and $0.90 \%)$ were measured by indirect potentiometry (Roche Diagnostics, Switzerland). Ionized calcium ( 0.80 and $0.60 \%$ ) was measured by direct potentiometry (ABL 800, Radiometer Medical). Intact PTH was assessed by immunoassay (Immulite, Siemens). Plasma renin activity was measured by radioimmunoassay of generated concentration of angiotensin I using a commercial kit (RENCTK ${ }^{\circledR}$; DiaSorin Inc., Stillwater, MN, USA). Measurement of aldosterone in the blood was performed with a commercial RIA (Coat-A-Count ${ }^{\circledR}$ Aldosterone kit, Siemens Medical Solutions Diagnostics; Los Angeles, CA, USA).

\section{Expression of NKCC1 and NKCC2 in parathyroid tissue}

Total messenger RNA (mRNA) was obtained from human parathyroid adenoma tissue (CR559081, OriGene, Rockville, MD, USA). One microgram of RNA was reverse-transcribed (PrimeScript RT reagent kit, Takara Bio Inc.) according to the manufacturer's instructions. TaqMan Gene Expression Assays (Applied Biosystems) were used to detect NKCC1, NKCC2, PTH, PTHR1, and actin, and quantitative real-time PCRs were carried out on an ABI PRISM 7500 equipment (Applied Biosystems, Carlsbad, CA) in triplicate for each sample, using TaqMan Universal PCR Master Mix (Applied Biosystems) in a final volume of $20 \mu \mathrm{l}$. Results are expressed as relative values to actin and to PTH using the $2^{-\Delta \Delta \mathrm{CT}}$ method.

\section{Statistics}

\section{Sample size calculation}

Stata 12 (StataCorp LP, Texas, USA) was used prior to the study for power and sample size calculation as well for the statistical analysis of the results.

The hypothesis of this study was based on the assumption that the calcimimetic blunts the PTH response to furosemide. Thus, the power of the study was calculated based on the changes in plasma PTH in the different groups. The increase in PTH levels after furosemide was assumed to have a normal distribution; the sample size calculation was therefore based on two-sample $t$ test. Our hypothesis was an almost twofold basal change of PTH after furosemide in control group as observed in animals (i.e., in terms of absolute values of PTH, an increase of $30 \mathrm{ng} / 1$ from 30 to $60 \mathrm{ng} / \mathrm{l})$. In the other group where the subjects were pretreated with cinacalcet, basal PTH is assumed to be decreased by $80 \%$ compared to placebo and is expected to reach about $6 \mathrm{ng} / \mathrm{l}$ before furosemide stimulation and $12 \mathrm{ng} / \mathrm{l}$ after. Standard deviation of $75 \%$ of these increased values was used in the calculation. Based on these hypotheses with 12 evaluable subjects, the study has $90 \%$ power to detect a change of this magnitude at a $5 \%$ significance level (two-sided).

Analysis of the data revealed that there was neither sequence nor crossover effect. There was no significant difference in baseline characteristics between participants beginning with cinacalcet and the others.

Data are reported as mean $\pm \mathrm{SD}$ or as median and interquartile range when appropriate. Comparisons between the different treatment groups were performed by analysis of the area under the curve and Wilcoxon rank test. A $p$ value less than 0.05 was considered significant.

Because the limit of quantification (LOQ) of iPTH at $3 \mathrm{ng} / 1$ was higher than levels measured in the majority of samples harvested in subjects treated with cinacalcet, the levels of iPTH in these latter samples were fixed at $1.5 \mathrm{ng} / \mathrm{l}$ for analysis, which is half of LOQ, a common strategy to replace censored data in distribution. This way to substitute censored data is rather conservative but also decreases variability. Therefore, nonparametric tests were used to compare iPTH between groups.

\section{Results}

Thirteen subjects received cinacalcet $(\mathrm{C})$ or placebo $(\mathrm{P})$ at baseline $(\mathrm{H}-3)$ and furosemide $(\mathrm{F}+) 3 \mathrm{~h}$ later at $\mathrm{H} 0(\mathrm{C} / \mathrm{F}+$ and $\mathrm{P} / \mathrm{F}+$ groups), while five subjects followed the same protocol, but without receiving furosemide $(\mathrm{P} / \mathrm{F}-$ and $\mathrm{C} / \mathrm{F}-$ groups). There was no difference in terms of age (27 \pm 5 vs $23 \pm 4$ years $),$ BMI $\left(22.0 \pm 2.0\right.$ vs $\left.21.8 \pm 1.7 \mathrm{~kg} / \mathrm{m}^{2}\right)$, systolic blood pressure ( $122 \pm 13$ vs $127 \pm 5 \mathrm{mmHg})$, diastolic blood pressure $(70 \pm 8$ vs $65 \pm 7 \mathrm{mmHg})$, and heart rate $(66 \pm 12$ vs $66 \pm 12 \mathrm{bpm})$ at inclusion visit between the 13 volunteers subjected to furosemide injection and the five individuals who did not receive furosemide.

Baseline clinical characteristics of the subjects and the results of the baseline $24 \mathrm{~h}$ urine collection are shown in Table 1 . All values were within normal range, and there was no significant difference between the groups except for serum creatinine which was slightly higher in the $\mathrm{C} / \mathrm{F}$ - group, due to one subject who was slightly dehydrated. His creatinine reached normal values after rehydration.

Changes in serum PTH levels for the four subgroups are illustrated over time on Fig. 1. In the placebo group, a decrease in PTH was observed before the administration of furosemide 
Table 1 Baseline characteristics of participants at the beginning of each investigation day of the crossover design

\begin{tabular}{|c|c|c|c|c|c|c|}
\hline & \multicolumn{3}{|c|}{ With furosemide $(N=13)$} & \multicolumn{3}{|c|}{ Without furosemide $(N=5)$} \\
\hline & Cinacalcet & Placebo & $P$ & Cinacalcet & Placebo & $P$ \\
\hline \multicolumn{7}{|l|}{ Serum } \\
\hline iPTH (ng/l) & $38.0 \pm 12.0$ & $42.7 \pm 15.5$ & NS & $51.2 \pm 19.9$ & $55.4 \pm 23.0$ & NS \\
\hline PRA (ng/ml/h) & $1.73 \pm 1.20$ & $2.60 \pm 1.68$ & NS & $2.66 \pm 1.50$ & $2.80 \pm 1.09$ & NS \\
\hline Aldosterone (pg/ml) & $482 \pm 252$ & $454 \pm 243$ & NS & $434 \pm 271$ & $492 \pm 221$ & NS \\
\hline \multicolumn{7}{|l|}{ Plasma } \\
\hline Creatinine $(\mu \mathrm{mol} / \mathrm{l})$ & $87.2 \pm 7.4$ & $88.4 \pm 9.9$ & NS & $94.2 \pm 12.9$ & $88.0 \pm 10.8$ & 0.01 \\
\hline Albumin (g/l) & $47.7 \pm 3.2$ & $47.5 \pm 2.6$ & NS & $48.8 \pm 1.5$ & $49.6 \pm 1.3$ & NS \\
\hline $\mathrm{Na}^{+}(\mathrm{mmol} / \mathrm{l})$ & $140 \pm 1$ & $140 \pm 1$ & NS & $141 \pm 1.2$ & $140 \pm 1$ & NS \\
\hline $\mathrm{K}^{+}(\mathrm{mmol} / \mathrm{l})$ & $3.8 \pm 0.3$ & $3.9 \pm 0.2$ & NS & $3.9 \pm 0.5$ & $4.1 \pm 0.3$ & NS \\
\hline Ca total $(\mathrm{mmol} / \mathrm{l})$ & $2.3 \pm 0.1$ & $2.3 \pm 0.1$ & NS & $2.3 \pm 0.1$ & $2.3 \pm 0.1$ & NS \\
\hline $\mathrm{Ca}^{++}$ionized $(\mathrm{mmol} / \mathrm{l})$ & $1.1 \pm 0.1$ & $1.2 \pm 0.1$ & NS & $1.1 \pm 0.1$ & $1.2 \pm 0.1$ & NS \\
\hline Ca corrected $(\mathrm{mmol} / \mathrm{l})$ & $2.2 \pm 0.1$ & $2.2 \pm 0.1$ & NS & $2.2 \pm 0.08$ & $2.2 \pm 0.1$ & NS \\
\hline Phosphate (mmol/l) & $1.2 \pm 0.1$ & $1.2 \pm 0.1$ & NS & $1.3 \pm 0.2$ & $1.3 \pm 0.2$ & NS \\
\hline \multicolumn{7}{|l|}{$24 \mathrm{~h}$ urine } \\
\hline Creatinine ( $\mu \mathrm{mol} /$ day) & $13^{\prime} 432 \pm 3^{\prime} 183$ & $13^{\prime} 835 \pm 3^{\prime} 752$ & NS & $14,655 \pm 2043$ & $15^{\prime} 374 \pm 3^{\prime} 210$ & NS \\
\hline $\mathrm{Na}^{+}(\mathrm{mmol} /$ day $)$ & $52.8 \pm 29.6$ & $59.4 \pm 43.6$ & NS & $31.4 \pm 18.3$ & $40.1 \pm 20.9$ & NS \\
\hline $\mathrm{K}^{+}(\mathrm{mmol} / \mathrm{day})$ & $72.8 \pm 28.2$ & $84.7 \pm 29.2$ & NS & $72.0 \pm 20.8$ & $40.6 \pm 23.0$ & NS \\
\hline $\mathrm{Ca}^{++}$(mmol/day) & $1.5 \pm 1.3$ & $1.2 \pm 0.9$ & NS & $0.2 \pm 0.1$ & $8.7 \pm 11.0$ & NS \\
\hline Phosphate (mmol/day) & $36.0 \pm 18.0$ & $34.1 \pm 16.2$ & NS & $40.1 \pm 8.5$ & $31.2 \pm 10.3$ & NS \\
\hline
\end{tabular}

$i P T H$ intact parathyroid hormone, $P R A$ plasma renin activity, $\mathrm{Na}^{+}$sodium, $\mathrm{K}^{+}$potassium, $\mathrm{Ca}^{++}$calcium in phase with the physiological diurnal variations of PTH [7] from (median; interquartile range (iqr)) $59.0 \mathrm{ng} / 1(52.0 ; 61.0)$ at $\mathrm{H}-3$ to $20.0 \mathrm{ng} / \mathrm{l}(16.0 ; 24.0)$ at $\mathrm{H} 0(p=0.002)$ in $\mathrm{P} / \mathrm{F}+$ subgroup and from $63.0(40.0 ; 69.0) \mathrm{ng} / \mathrm{l}$ at $\mathrm{H}-3$ to 25.0 $(19.0 ; 35.0) \mathrm{ng} / \mathrm{l}$ at $\mathrm{H} 0(p=0.043)$ in $\mathrm{P} / \mathrm{F}-$ subgroup. During the same time period, the administration of cinacalcet induced

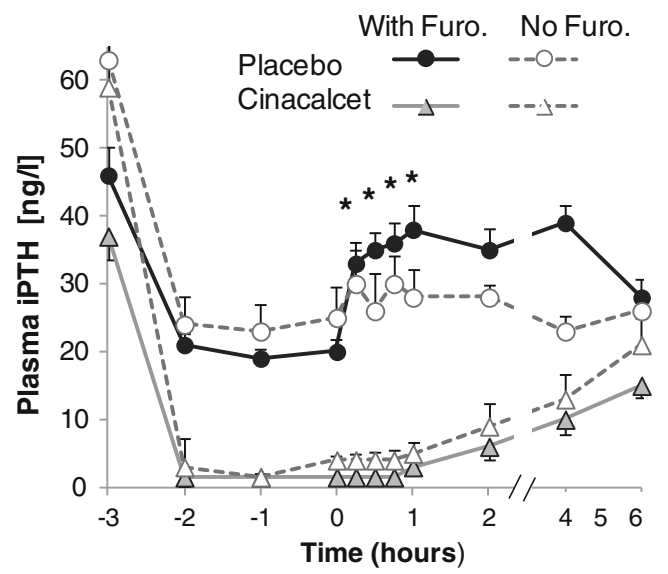

Fig. 1 Plasma iPTH profile according to subgroups during the investigation day. Plasma iPTH decreases in all groups but reaches below normal values in subjects under cinacalcet. Furosemide injection acutely stimulates $\mathrm{PTH}$ secretion in $\mathrm{P} / \mathrm{F}+$ subgroup. This effect is blunted in $\mathrm{C} / \mathrm{F}+$ subgroup. Furosemide was injected at time 0 . Values are medians \pm SEM. ${ }^{*} p \leq 0.01$ for difference between time 0 (furosemide injection) and following time points. All values between placebo and $\mathrm{C} / \mathrm{F}+$ are significantly different from time 0 to $6 \mathrm{~h}$ using Wilcoxon signed rank test a rapid and marked decrease of serum PTH, which reached levels below the lower range limit in most of the subjects after $3 \mathrm{~h}$ : from $37.0(33.0 ; 42.0) \mathrm{ng} / \mathrm{l}$ at $\mathrm{H}-3$ to $1.5(1.5 ; 1.5) \mathrm{ng} / \mathrm{l}$ at $\mathrm{H} 0(p=0.002)$ in $\mathrm{C} / \mathrm{F}+$ subgroup and from $46.0(35.0 ; 49.0)$ $\mathrm{ng} / \mathrm{l}$ to $4.0(1.5 ; 4.0) \mathrm{ng} / \mathrm{l}(p=0.043)$ in $\mathrm{C} / \mathrm{F}-$ subgroup.

The injection of furosemide produced a sharp increase in plasma PTH levels in subjects under placebo $(\mathrm{P} / \mathrm{F}+)$ from (median; iqr) $20.0(16.0 ; 24.0) \mathrm{ng} / \mathrm{l}$ at $\mathrm{H} 0$ to 38.0 (33.0; $48.0) \mathrm{ng} / \mathrm{l}$ at $\mathrm{H} 1 \quad(p=0.001)$. The furosemide effect on PTH persisted during $3 \mathrm{~h}$. In subjects preexposed to cinacalcet ( $\mathrm{C} / \mathrm{F}+$ subgroup), the PTH response to furosemide did only change from $1.5(1.5 ; 1.5) \mathrm{ng} / \mathrm{l}$ at $\mathrm{H} 0$ to $3.0(1.5 ; 1.9) \mathrm{ng} / \mathrm{l}$ at H1 $(p=0.071)$, whereas no PTH change was observed in furosemide-naive subjects, passing from $4.0(1.5 ; 4.0) \mathrm{ng} / \mathrm{l}$ at $\mathrm{H} 0$ to $5.0(1.5 ; 7.0) \mathrm{ng} / \mathrm{l}$ at $\mathrm{H} 1(p=0.17) \mathrm{in} \mathrm{C} / \mathrm{F}-$ subgroup and from $25.0(19.0 ; 35.0) \mathrm{ng} / \mathrm{l}$ at $\mathrm{H} 0$ to $28.0(23.0 ; 37.0) \mathrm{ng} / \mathrm{l}$ at $\mathrm{H} 1(p=0.06)$ in the $\mathrm{P} / \mathrm{F}-$ subgroup.

We measured the area under the curve (AUC) of plasma PTH between $\mathrm{H} 0$ and $\mathrm{H} 6$ in the four subgroups and found that subjects on placebo receiving furosemide showed significantly higher values as compared to other subgroups (Supplemental Fig. S1): (mean \pm SD) $1248 \pm 404 \mathrm{~min}$ ng/l in $\mathrm{P} / \mathrm{F}+$ vs $447 \pm$ $319 \mathrm{~min} \mathrm{ng} / \mathrm{l}$ in $\mathrm{C} / \mathrm{F}+(p=0.003)$ and $320 \pm 273 \mathrm{~min} \mathrm{ng} / \mathrm{l}$ in $\mathrm{P} / \mathrm{F}$ $-(p=0.003 \mathrm{vs} \mathrm{P} / \mathrm{F}+)$ and $452 \pm 363 \mathrm{~min} \mathrm{ng} / \mathrm{l}$ in $\mathrm{C} / \mathrm{F}-(p=0.007$ vs $\mathrm{P} / \mathrm{F}+)$. This further demonstrates that furosemide stimulates PTH secretion in humans and that this effect was not observed under cinacalcet. 
To decipher the mechanisms underlying the increase of PTH levels induced by furosemide, variations in serum ionized calcium and in urinary calcium excretion were measured (Fig. 2). In the $\mathrm{P} / \mathrm{F}+$ group, no significant change in plasma ionized calcium was observed between baseline and the peak effect of furosemide $(1.19 \pm 0.06 \mathrm{mmol} / \mathrm{l}$ at $\mathrm{H} 0$ and $1.19 \pm$ $0.03 \mathrm{mmol} / 1$ at $\mathrm{H} 1 ;$ mean $\pm \mathrm{SD}$ ). In the $\mathrm{C} / \mathrm{F}+$ group, a decrease in plasma calcium was observed from $1.17 \pm 0.04$ at $\mathrm{H} 0$ to $1.15 \pm 0.04 \mathrm{mmol} / \mathrm{l}$ at $\mathrm{H} 1$ ( $p=0.008$ ) (Fig. 2a). No significant change in ionized calcium was seen in participants who did not receive furosemide (groups $\mathrm{C} / \mathrm{F}-$ and $\mathrm{P} / \mathrm{F}-$ ). Taken together, these results strongly suggest that the change in PTH concentration observed in the $\mathrm{P} / \mathrm{F}+$ group cannot be attributed to variations of serum calcium.

Furosemide induced a significant increase in urinary calcium excretion which was similar under cinacalcet or placebo (Fig. 2b). No change in calciuria was found in subjects who did not receive furosemide. There was no relevant difference between subjects under cinacalcet and placebo, when comparing the subgroups exposed to furosemide $(\mathrm{P} / \mathrm{F}+\mathrm{vs} \mathrm{C} / \mathrm{F}+, p=0.27)$ or between furosemide-naive subgroups $(\mathrm{P} / \mathrm{F}-\mathrm{vs} \mathrm{C} / \mathrm{F}-, p=0.50)$.

Plasma sodium and potassium profiles were comparable between the groups during the whole investigation day (supplemental Fig. S2). After furosemide injection, a slight but nonsignificant decrease in serum potassium was observed with no change in plasma sodium. Plasma phosphate and magnesium showed comparable values between subgroups and were not influenced by cinacalcet or furosemide treatments (data not shown).

Figure $3 \mathrm{a}, \mathrm{b}$ summarizes changes in urinary sodium and potassium over time. As expected, furosemide induced a sharp increase of urinary sodium and potassium excretion both under placebo and cinacalcet.

We further address the impact of cinacalcet and furosemide on plasma renin activity (PRA, Fig. 4a) and plasma aldosterone levels (Fig. 4b). Before the administration of furosemide, a parallel decrease of the two parameters was observed, probably due to the variation of the hydration status and the known circadian variations of these hormones.

In both $\mathrm{P} / \mathrm{F}+$ and $\mathrm{C} / \mathrm{F}+$ subgroups, furosemide induced a rapid and significant increase in plasma renin activity which peaked after $15 \mathrm{~min}$.

In furosemide-naive groups, no difference between placebo or cinacalcet-treated groups and no change in PRA was observed. As shown in Fig. 4b, we have also investigated the changes in plasma aldosterone which followed a similar pattern as PRA. Again, no significant difference was found between $\mathrm{P} / \mathrm{F}+$ and $\mathrm{C} / \mathrm{F}+$, although in $\mathrm{C} / \mathrm{F}+$, plasma aldosterone levels tended to be lower at $\mathrm{H} 0$ and for the next $2 \mathrm{~h}$.

Finally, we assessed whether parathyroid tissue expresses the furosemide-targeted transporters NKCC1 or NKCC2. Quantitative PCR was performed on reversed transcribed RNA obtained from parathyroid tissue of an excised adenoma.
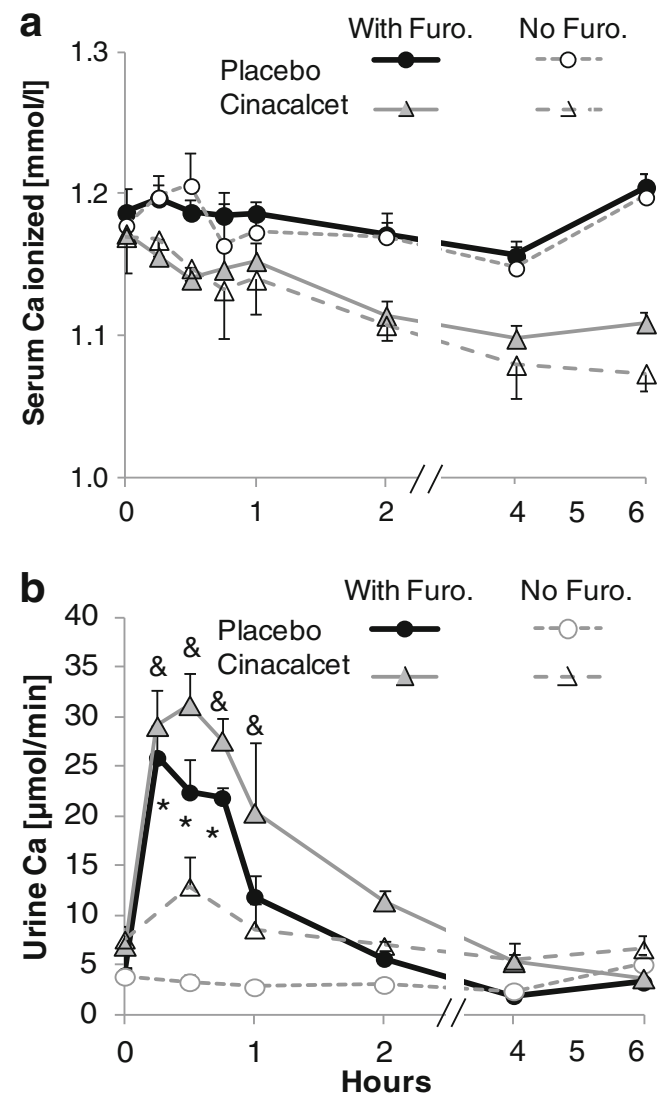

Fig. 2 Variations in plasma ionized calcium profile (a) and urine calcium profile (b) in the different subgroups during the investigation day. No significant change in ionized calcium values occurs in $\mathrm{P} / \mathrm{F}+$ subgroup, whereas a significant decrease is noted in $\mathrm{C} / \mathrm{F}+$ subgroup that suggests that PTH increase is not linked to plasma ionized calcium values. Both F+ groups show a significant acute increase in calciuria which does not occur in $\mathrm{F}$ - subgroups. $\mathrm{P} / \mathrm{F}-$ placebo subgroup; $\mathrm{C} / \mathrm{F}-$ cinacalcet subgroup; $\mathrm{P} / \mathrm{F}+$ placebo/furosemide subgroup; $\mathrm{C} / \mathrm{F}+$ cinacalcet/furosemide subgroup; Furosemide was injected at time 0 . Values are means $\pm \mathrm{SEM}$. ${ }^{*} p<0.05$ between $\mathrm{P} / \mathrm{F}+$ and $\mathrm{P} / \mathrm{F}-$ subgroups. \& $p<0.05$ between $\mathrm{C} / \mathrm{F}+$ and $\mathrm{C} / \mathrm{F}-$

PTH was strongly expressed as expected, as well as PTH receptor (PTHR1) and NKCC1, while NKCC2 was not detected (Fig. 5).

\section{Discussion}

We showed here that an acute administration of the loop diuretic furosemide increases plasma PTH levels in healthy humans in the absence of any measurable changes in serum ionized calcium or other plasma electrolytes. The PTH response to furosemide was blunted by the previous administration of the calcimimetic cinacalcet despite a slight decrease in plasma ionized calcium induced by cinacalcet. In contrast to animal studies, cinacalcet does not appear to blunt the stimulatory effect of furosemide on renin secretion. However, plasma aldosterone levels were lower after administration of 

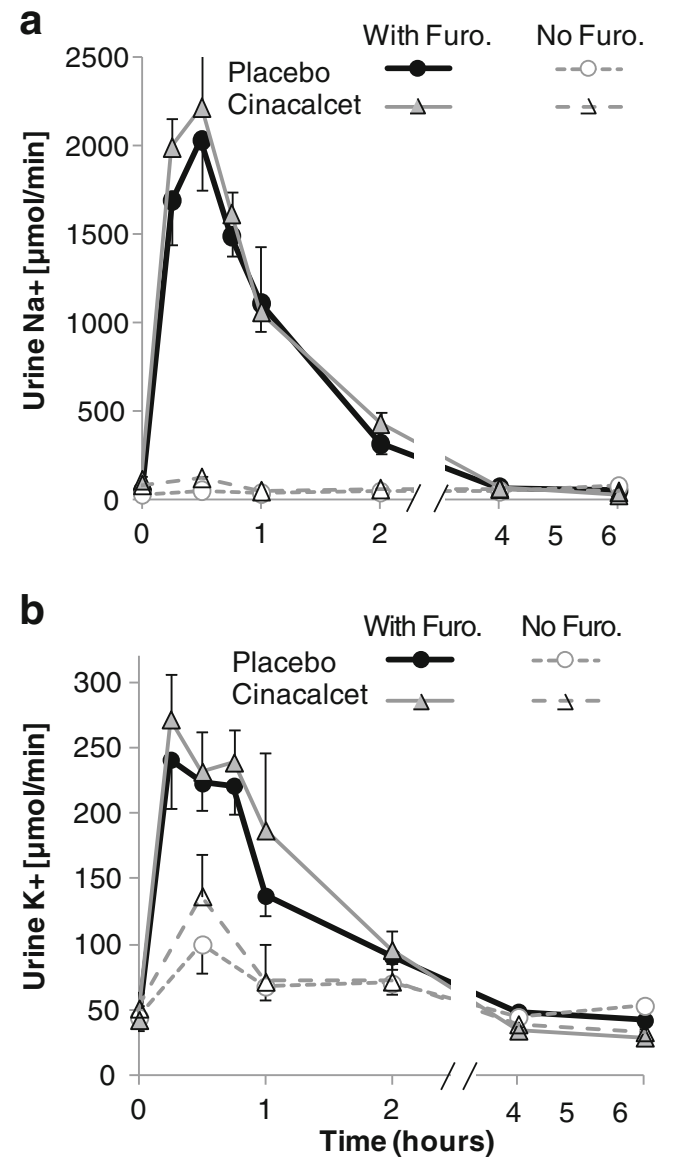

Fig. 3 Urinary sodium (a), and urinary potassium excretions (b) in the various subgroups during the investigation day. All subjects show a similarly increased excretion of sodium and potassium after furosemide injection, whether there are under cinacalcet or placebo. $\mathrm{Na}^{+}$sodium, $\mathrm{K}^{+}$ potassium. Furosemide was injected at time 0 . Values are means \pm SEM. All values between placebo and $\mathrm{C} / \mathrm{F}+$ are significantly different from time 0 to $1 \mathrm{~h}$ using Wilcoxon signed rank test

cinacalcet. And, the time course of PTH levels after furosemide correlated with the changes in PRA and aldosterone. Whether cinacalcet is mediating the effect of furosemide on PTH via renin-angiotensin-aldosterone system remains uncertain. At last, transient variations in plasma sodium and potassium do not appear to be associated with the change in PTH induced by furosemide.

Several hypotheses have been proposed to explain furosemide-induced PTH secretion. (i) By increasing calciuria and slightly decreasing calcemia, furosemide could stimulate PTH secretion in the parathyroid gland [8]. (ii) Following furosemide injection, volume depletion and stimulation of the renin-angiotensin-aldosterone system could lead to increased PTH secretion by mechanisms not yet well understood $[3,9,11]$. (iii) Furosemide, by changing plasma potassium levels, could interfere with the $\mathrm{Na}^{+} / \mathrm{K}^{+}$-APTase activity, which is known to regulate PTH secretion in the parathyroid tissue [2]. (iv) Finally, furosemide could act directly on the parathyroid glands and stimulate PTH secretion.
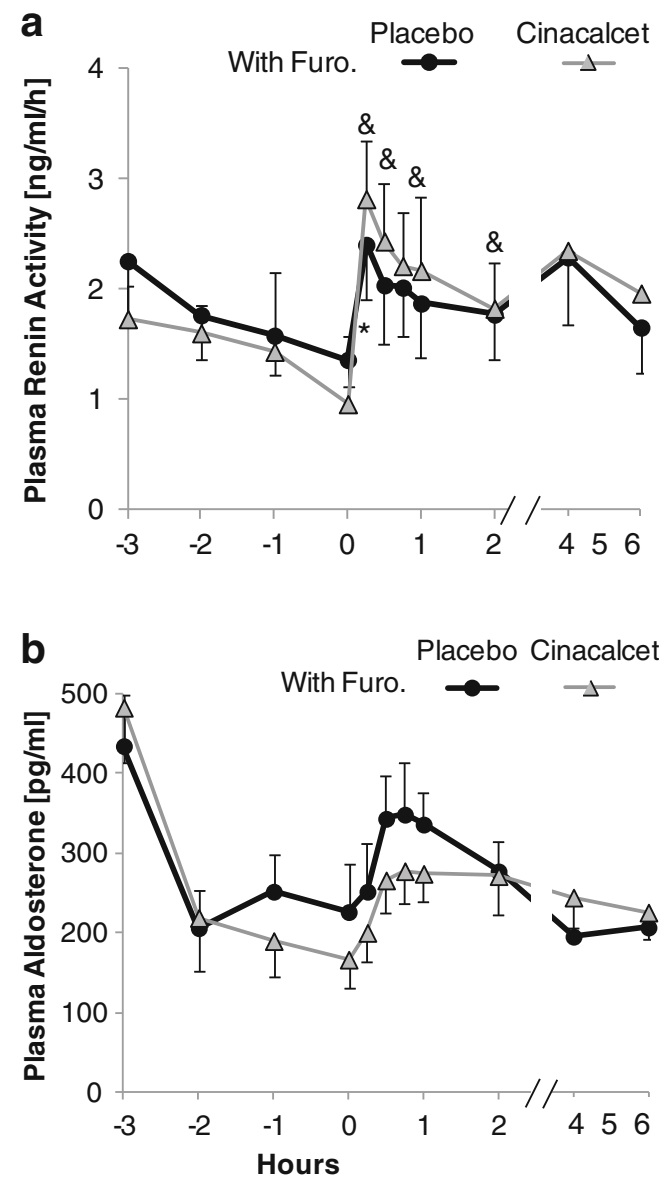

Fig. 4 Plasma renin activity (a) and plasma aldosterone (b) according to furosemide-injected subgroups during the investigation day. In both subgroups, plasma renin activity and plasma aldosterone values decrease in the first hours of the investigation days. However, plasma renin activity increases significantly as soon as $15 \mathrm{~min}$ after injection whereas it remains stable in furosemide-naive subgroups (not shown here for clarity reasons). Plasma aldosterone tends to a similar pattern but without reaching significantly different values. Furosemide was injected at time 0 . Values are means \pm SEM. ${ }^{*} p<0.05 \mathrm{P} / \mathrm{F}+$ vs time at $\mathrm{H} 0 . \& p<0.05$ between $\mathrm{C} / \mathrm{F}+$ vs time at $\mathrm{H} 0$

In previously published papers describing the ability of furosemide to stimulate PTH $[28,10]$, the more simple hypothesis was that the increase in calciuria provoked by furosemide through its action on Henle's loop would lead to

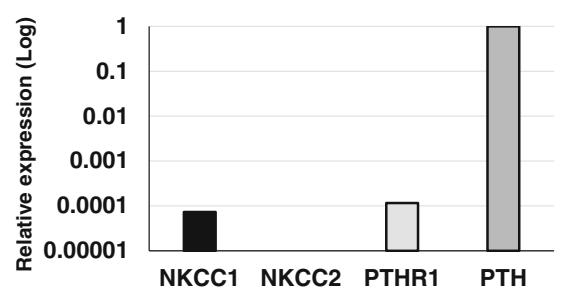

Fig. 5 NKCC1, but not NKCC2 mRNA, is expressed in human parathyroid tissue. Messenger RNA was obtained from human parathyroid adenoma, and $\mathrm{NKCC} 1$ and $\mathrm{NKCC} 2$ expressions were assessed by quantitative PCR. NKCC2 was not detectable. PTH and PTHR1 served as controls and are strongly expressed. Expression is related to actin and to PTH expression 
transient hypocalcemia which stimulates PTH release. In line with this hypothesis, Reichel et al. found that in an anuric patient, furosemide had no effect on PTH [27]. In addition, the administration of hydrochlorothiazide, which reduces urinary calcium excretion, was not associated with any change in PTH [31]. However, total as well as ionized plasma calcium levels remained unchanged after furosemide administration in these studies. A similar observation was made in our study in which we found a clear stimulation of PTH and hypercalciuria after furosemide treatment, but without any detectable change in serum ionized calcium. This suggests that calcemia may not be the link between calciuria and PTH release, unless very rapid and transient variations in calcemia occur and are under the detection threshold of our protocol. This could be the case if an immediate pool of calcium is mobilized from the bone, as suggested by some authors [26]. Against a prominent role of serum calcium stands our observation that in the cinacalcet group, PTH release after furosemide is blunted despite a rise in urinary calcium excretion and a decrease in plasma ionized calcium. The finding that a single dose of the calcimimetic cinacalcet given $3 \mathrm{~h}$ before furosemide almost abolishes the PTH response to furosemide suggests that calcium sensing is, to some degree, involved in the response to furosemide but does not allow concluding on the precise role of calcium.

We investigated the interaction between furosemide, PTH, and the renin-angiotensin-aldosterone system and evaluated the role of CaSR. Indeed, calcium-sensing receptors are expressed in juxtaglomerular cells in mice [23] and rats [18]. Recent findings in humans indicate that there is a tight link between the RAAS and the parathyroid glands, suggesting that the RAAS may mediate the furosemide effect on PTH secretion $[4,15,16,19,20,22,29]$. In a previous experimental study, we demonstrated that administration of the calcimimetic RS568 inhibited renin secretion in rats and blunted the renin response induced by furosemide [18]. The calcimimetic also blunted the PTH response to furosemide. For these reasons, we have investigated the impact of cinacalcet on the renin response to furosemide and whether renin or aldosterone could be mediators of the furosemide effect on PTH release. In contrast to what was observed in the rat, cinacalcet did not inhibit the renin response to furosemide in our healthy subjects. Of note however, a strong positive association between PTH and renin, as evidenced by the similar kinetic of the hormones along the study procedure, was observed with an interesting synchronous course after furosemide injection. A similar synchrony was found between aldosterone and PTH, with a slight delay [9, 3]. These observations could have led to the speculation of a possible implication of the RAAS in the furosemide-mediated PTH response. But, in calcimimetic-receiving subjects, renin and aldosterone responses to furosemide were intact excluding renin and aldosterone as a mediator of the furosemide effect. Regarding the possible role of aldosterone, the situation is however more complex. Indeed, plasma aldosterone levels were lower upon administration of cinacalcet and remained lower after the injection of furosemide. Whether the reduction in plasma aldosterone induced by cinacalcet has contributed to the blunting of PTH in the $\mathrm{C} / \mathrm{F}+$ group is thus possible but not ascertained by our data.

Looking for other mechanisms mediating the furosemide increase in PTH, we explored the role of changes in serum electrolytes namely sodium, potassium, magnesium, and phosphate. Brown et al. have shown in vitro that hypokalemia and the exposure to ouabain, a specific inhibitor of the $\mathrm{Na}^{+}-\mathrm{K}^{+}$ ATPase, inhibited PTH secretion in isolated bovine parathyroid cells [1, 2]. More recently, Imura [14] demonstrated the involvement of $\alpha$-klotho in calcium-dependent trafficking of the $\mathrm{Na}^{+}-\mathrm{K}^{+}$ATPase to the cell surface of the parathyroid gland's chief cells. These results suggest that the electrochemical gradient created by the klotho-dependent increase in cell surface expression of the $\mathrm{Na}^{+}-\mathrm{K}^{+}$ATPase participates in the regulation of PTH secretion. This pathway is disrupted either in state of $\alpha$-klotho deficiency or in case of ouabain exposure. Thus, hypokalemia may be associated with PTH secretion through the action of $\mathrm{Na}^{+}-\mathrm{K}^{+}$ATPase. However, more recent data in rats questioned the regulating action of $\mathrm{Na}^{+}-\mathrm{K}^{+}$ATPase on parathyroid activity [21]. In our study, no significant change in plasma sodium and magnesium were found, thus excluding a role of these electrolytes. A trend toward lower potassium levels was noted but was of similar magnitude between placebo- and cinacalcet-treated subjects, rejecting a major role of hypokalemia and of the $\mathrm{Na}^{+}-\mathrm{K}^{+}$ATPase in the increase of PTH.

Finally, furosemide may act directly on the parathyroid gland tissue, given that sodium-potassium-chloride cotransporters (NKCCs) are ubiquitously expressed. No evidence supporting this hypothesis has been provided so far, but we demonstrated here that the parathyroid tissue expresses NKCC1 mRNA, but not the kidney-specific gene NKCC2. This raises the possibility of a direct role of furosemide acting on the parathyroid gland, as previously shown for the juxtaglomerular apparatus by Castrop et al. [5]. NKCC1 has a $K i$ for furosemide in the micromolar range, compatible with plasma concentrations that can be rapidly reached after furosemide injection [12]. Further experiments testing this hypothesis need now to be conducted.

Limitations of this study include the low number of volunteers, however reaching the calculated number for full power analysis, and the lack of measurement of $1,25(\mathrm{OH})_{2}$-vitamin D. The fact that cinacalcet inhibited PTH to very low levels rendered the interpretation of the data more delicate, particularly with regard to PTH stimulation. However, we feel that even if cinacalcet significantly reduced PTH levels, the overall conclusions of the study are not affected.

In conclusion, the furosemide-induced acute increase of PTH (doubling in less than $15 \mathrm{~min}$ ) was ascertained in humans 
by this study. If the mechanism behind this observation remains unclear, we provide here insights in several working hypotheses. First, we did not observe changes in plasma calcium levels, excluding hypocalcemia as the main trigger for PTH increase. Second, we did not observe a clear correlation between the RAAS and PTH increase, suggesting only weak interaction between the two systems during furosemide stimulation in humans. Third, we did not identify any change in plasma electrolytes that could influence $\mathrm{Na}^{+} / \mathrm{K}^{+}$-ATPase function involved in abnormal PTH secretion. Fourth, we show that human parathyroid tissue expresses the furosemide-target gene NKCCl, which may modulate PTH secretion. Finally, we showed that furosemide-induced PTH secretion is dependent upon calcium-sensing receptor function. This further emphasizes the role of CaSR at the interface between both calcium and sodium regulatory systems.

Acknowledgements This study was funded by a grant of the National Center of Competence in Research "Kidney Control of Homeostasis" of the Swiss National Science Foundation (to OB and MB).

Conflict of interest There was no conflict of interest.

\section{References}

1. Brown EM, Jones P, Adragna N (1983) Effects of ouabain on $[3 \mathrm{H}]$ ouabain binding, $86 \mathrm{Rb}$ uptake, cellular sodium and potassium, and parathyroid hormone secretion in dispersed bovine parathyroid cells. Endocrinology 113(1):371-378

2. Brown EM, Watson EJ, Thatcher JG, Koletsky R, Dawson-Hughes BF, Posillico JT, Shoback DM (1987) Ouabain and low extracellular potassium inhibit PTH secretion from bovine parathyroid cells by a mechanism that does not involve increases in the cytosolic calcium concentration. Metab Clin Exp 36(1):36-42

3. Brown JM, Williams JS, Luther JM, Garg R, Garza AE, Pojoga LH, Ruan DT, Williams GH, Adler GK, Vaidya A (2014) Human interventions to characterize novel relationships between the reninangiotensin-aldosterone system and parathyroid hormone. Hypertension 63(2):273-280. doi:10.1161/HYPERTENSIONAHA. 113.01910

4. Brunaud L, Germain A, Zarnegar R, Rancier M, Alrasheedi S, Caillard C, Ayav A, Weryha G, Mirallie E, Bresler L (2009) Serum aldosterone is correlated positively to parathyroid hormone (PTH) levels in patients with primary hyperparathyroidism. Surgery 146(6):1035-1041. doi:10.1016/j.surg.2009.09.041

5. Castrop H, Lorenz JN, Hansen PB, Friis U, Mizel D, Oppermann M, Jensen BL, Briggs J, Skott O, Schnermann J (2005) Contribution of the basolateral isoform of the Na-K-2Cl- cotransporter (NKCC1/ BSC2) to renin secretion. Am J Physiol Ren Physiol 289(6): F1185-F1192. doi:10.1152/ajprenal.00455.2004

6. Coe FL, Canterbury JM, Firpo JJ, Reiss E (1973) Evidence for secondary hyperparathyroidism in idiopathic hypercalciuria. J Clin Invest 52(1):134-142. doi:10.1172/JCI107156

7. el-Hajj Fuleihan G, Klerman EB, Brown EN, Choe Y, Brown EM, Czeisler CA (1997) The parathyroid hormone circadian rhythm is truly endogenous - a general clinical research center study. J Clin Endocrinol Metab 82(1):281-286
8. Elmgreen J, Tougaard L, Leth A, Christensen MS (1980) Elevated serum parathyroid hormone concentration during treatment with high ceiling diuretics. Eur J Clin Pharmacol 18(4):363-364

9. Fischer E, Hannemann A, Rettig R, Lieb W, Nauck M, Pallauf A, Bildingmaier M, Beuschlein F, Wallaschofski H, Reincke M (2014) A high aldosterone to renin ratio is associated with high serum parathyroid hormone concentrations in the general population. J Clin Endocrinol Metab 99(3):965-971. doi:10.1210/jc.2013-3214

10. Fujita T, Chan JC, Bartter FC (1984) Effects of oral furosemide and salt loading on parathyroid function in normal subjects. Physiological basis for renal hypercalciuria. Nephron 38(2):109114

11. Grant FD, Mandel SJ, Brown EM, Williams GH, Seely EW (1992) Interrelationships between the renin-angiotensin-aldosterone and calcium homeostatic systems. J Clin Endocrinol Metab 75(4): 988-992

12. Haegeli L, Brunner-La Rocca HP, Wenk M, Pfisterer M, Drewe J, Krahenbuhl S (2007) Sublingual administration of furosemide: new application of an old drug. Br J Clin Pharmacol 64(6):804-809. doi: 10.1111/j.1365-2125.2007.03035.x

13. Hufnagle KG, Khan SN, Penn D, Cacciarelli A, Williams P (1982) Renal calcifications: a complication of long-term furosemide therapy in preterm infants. Pediatrics 70(3):360-363

14. Imura A, Tsuji Y, Murata M, Maeda R, Kubota K, Iwano A, Obuse C, Togashi K, Tominaga M, Kita N, Tomiyama K, Iijima J, Nabeshima Y, Fujioka M, Asato R, Tanaka S, Kojima K, Ito J, Nozaki K, Hashimoto N, Ito T, Nishio T, Uchiyama T, Fujimori T, Nabeshima Y (2007) alpha-Klotho as a regulator of calcium homeostasis. Science 316(5831):1615-1618. doi:10.1126/science. 1135901

15. Isales CM, Barrett PQ, Brines M, Bollag W, Rasmussen H (1991) Parathyroid hormone modulates angiotensin II-induced aldosterone secretion from the adrenal glomerulosa cell. Endocrinology 129(1): 489-495. doi:10.1210/endo-129-1-489

16. Jespersen B, Pedersen EB, Charles P, Danielsen H, Juhl H (1989) Elevated angiotensin II and vasopressin in primary hyperparathyroidism. Angiotensin II infusion studies before and after removal of the parathyroid adenoma. Acta Endocrinol (Copenh) 120(3):362368

17. Kim YG, Kim B, Kim MK, Chung SJ, Han HJ, Ryu JA, Lee YH, Lee KB, Lee JY, Huh W, Oh HY (2001) Medullary nephrocalcinosis associated with long-term furosemide abuse in adults. Nephrol Dial Transplant : Off Publ Eur Dial Transplant Assoc - Eur Ren Assoc 16(12):2303-2309

18. Maillard MP, Tedjani A, Perregaux C, Burnier M (2009) Calciumsensing receptors modulate renin release in vivo and in vitro in the rat. J Hypertens 27(10):1980-1987. doi:10.1097/HJH. 0b013e32832f0d22

19. Maniero C, Fassina A, Guzzardo V, Lenzini L, Amadori G, Pelizzo MR, Gomez-Sanchez C, Rossi GP (2011) Primary hyperparathyroidism with concurrent primary aldosteronism. Hypertension 58(3):341-346. doi:10.1161/HYPERTENSIONAHA.111.173948

20. Maniero C, Fassina A, Seccia TM, Toniato A, Iacobone M, Plebani M, De Caro R, Calo LA, Pessina AC, Rossi GP (2012) Mild hyperparathyroidism: a novel surgically correctable feature of primary aldosteronism. J Hypertens 30(2):390-395. doi:10.1097/HJH. 0b013e32834f0451

21. Martuseviciene G, Hofman-Bang J, Clausen T, Olgaard K, Lewin E (2011) The secretory response of parathyroid hormone to acute hypocalcemia in vivo is independent of parathyroid glandular sodium/potassium-ATPase activity. Kidney Int 79(7):742-748. doi:10.1038/ki.2010.501

22. Mazzocchi G, Aragona F, Malendowicz LK, Nussdorfer GG (2001) PTH and PTH-related peptide enhance steroid secretion from human adrenocortical cells. Am J Physiol Endocrinol Metab 280(2): E209-E213 
23. Ortiz-Capisano MC, Ortiz PA, Garvin JL, Harding P, Beierwaltes WH (2007) Expression and function of the calcium-sensing receptor in juxtaglomerular cells. Hypertension 50(4):737-743. doi:10. 1161/HYPERTENSIONAHA.107.095158

24. Osorio AV, Alon MM, Nichols MA, Alon US (1998) Effect of age on furosemide-induced nephrocalcinosis in the rat. Biol Neonate 73(5):306-312

25. Pattaragarn A, Fox J, Alon US (2004) Effect of the calcimimetic NPS R-467 on furosemide-induced nephrocalcinosis in the young rat. Kidney Int 65(5):1684-1689. doi:10.1111/j.1523-1755.2004.00564.x

26. Pirklbauer M, Mayer G (2011) The exchangeable calcium pool: physiology and pathophysiology in chronic kidney disease. Nephrol Dial Transplant : Off Publ Eur Dial Transplant Assoc Eur Ren Assoc 26(8):2438-2444. doi:10.1093/ndt/gfr207

27. Reichel H, Deibert B, Geberth S, Schmidt-Gayk H, Ritz E (1992) Frusemide therapy and intact parathyroid hormone plasma concentrations in chronic renal insufficiency. Nephrol Dial Transplant : Off Publ Eur Dial Transplant Assoc - Eur Ren Assoc 7(1):8-15
28. Rejnmark L, Vestergaard P, Heickendorff L, Andreasen F, Mosekilde L (2001) Loop diuretics alter the diurnal rhythm of endogenous parathyroid hormone secretion. A randomizedcontrolled study on the effects of loop- and thiazide-diuretics on the diurnal rhythms of calcitropic hormones and biochemical bone markers in postmenopausal women. Eur J Clin Investig 31(9):764772

29. Rosenberg J, Pines M, Hurwitz S (1987) Response of adrenal cells to parathyroid hormone stimulation. J Endocrinol 112(3):431-437

30. Saarela T, Lanning P, Koivisto M, Paavilainen T (1999) Nephrocalcinosis in full-term infants receiving furosemide treatment for congestive heart failure: a study of the incidence and 2year follow up. Eur J Pediatr 158(8):668-672

31. Stote RM, Smith LH, Wilson DM, Dube WJ, Goldsmith RS, Arnaud CD (1972) Hydrochlorothiazide effects on serum calcim and immunoreactive parathyroid hormone concentrations. Studies in normal subjects. Ann Intern Med 77(4): $587-591$ 